\title{
A robust AHP-DEA method for measuring the relative efficiency: An application of airport industry
}

\author{
Amin Foroughi $^{\mathbf{a}^{*}}$ and Mohammad Javad Esfahani ${ }^{\mathbf{b}}$
}

${ }^{a}$ Department of Industrial Engineering, Islamic Azad University, Naragh Branch, Naragh, Iran

${ }^{b}$ Young Researchers Club, Naragh Branch, Islamic Azad University, Naragh, Iran

\begin{tabular}{lll}
\hline A R T I C L E I N F O & A B S T R A C T \\
\cline { 3 - 3 } $\begin{array}{l}\text { Article history: } \\
\text { Received July 16, 2011 }\end{array} \begin{array}{l}\text { Measuring the relative efficiency of similar units has been an important topic of research among } \\
\text { many researchers. Data envelopment analysis has been one of the most important techniques for } \\
\text { September, 3, 2011 }\end{array}$ & $\begin{array}{l}\text { measuring the efficiency of different units. However, there are some limitations on using such } \\
\text { Accepted 18 September } 2011\end{array}$ & technique and some people prefer to use other methods such as analytical hierarchy process to \\
Available online & measure the relative efficiencies. Besides, uncertainty in the input data is another issue, which \\
29 September 2011 & makes some misleading results. In this paper, we present an integrated robust DEA-AHP to \\
\hline Keywords: & measure the relative efficiency of similar units. The proposed model of this is believed to \\
Data envelopment analysis & capable of presenting better results in terms of efficiency compared with exclusive usage of \\
Analytical hierarchy process & DEA or AHP. The implementation of the proposed model is demonstrated for a real-world case \\
DEA-AHP & study of Airport industry and the results are analyzed.
\end{tabular}

Robust optimization

\section{Introduction}

Data envelopment analysis (DEA) introduced by Charnes et al. $(1978,1994)$ is one of the most popular techniques for measuring the relative efficiency of similar non-financial units. The method uses various inputs/outputs and compares the relative efficiencies of all units through the optimal solution of linear programming problems. The method has been widely used among many researchers and there are literally various versions of this technique such constant return to scale (CRS) and variable return to return (VRS). There are also many real-world applications of DEA method in different industries. Sadjadi and Omrani (2008), for instance, used DEA method for measuring the relative efficiency of energy companies in Iran. Sadjadi and Omrani (2009) implemented DEA technique to determine the most efficient units of telecommunication firms in Iran. Roghanian and Foroughi (2010) implemented DEA for Airport industry in Iran and using different input/output, they compared all regional and international airports in Iran.

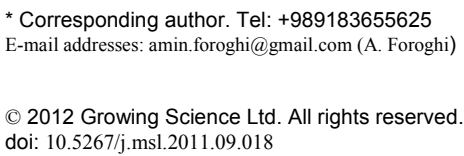


One of the most important issues associated with DEA is the uncertainty associated with the input data. Since the resulted problem formulation of DEA technique is in form of linear programming, one can use traditional sensitivity analysis in case there is one or a few unknown parameters. However, when all input data are subject to uncertainty, it is practically impossible to use old fashion methods to handle uncertainty. Thanks to recent advances of optimization technique, we may use the idea of robust optimization for linear programming to handle uncertainty, very easily.

Soyster (1972) is believed to be the first who introduced robust optimization to handle uncertainty but his approach was too pessimistic. Ben-Tal and Nemirovski (1999) introduced a remarkable technique based on the art of cone programming and it seems that their method provides very reliable solutions with limited amount of penalty. The method converts a simple linear programming problem into a nonlinear problem where one can use the recent advances of cone programming techniques to find the optimal solution. The method is believed to be one of the best techniques for handling uncertainty but one must be familiar with the concept of nonlinear programming to use these problems. Bertsimas and Sim (2003) proposed another version of the robust optimization without changing the structure of the resulted problem, i.e. for the case of DEA method the robust DEA maintains the linear form of the original problem.

Sadjadi and Omrani (2008) are also the first ones who introduced the idea of robust DEA for handling uncertainty in the data. They examined both robust methods introduced by Ben-Tal and Nemirovski (1999) and Bertsimas and Sim (2003) to handle uncertainty for two applications from energy and telecommunication industries and compared their results with the nominal solutions. They concluded that the price of robustness does not have significant impact of the quality of final results but it immunes the final solutions against data uncertainty, significantly.

There are several disadvantages associated with the DEA technique and some people try to use another multi-criteria technique to remove any possible shortcoming. Saaty (1980) introduced analytical hierarchy process (AHP) for ranking different alternatives based on different attributes. The idea is to make a pairwise comparison between each two alternatives for ranking choices. The integrated DEA and AHP has been widely used among many researchers. For instance, Che et al. (2010) implemented an integration of Fuzzy analytical hierarchy procedure (AHP) and DEA as a decision making facility for making bank loan decisions.

The proposed model of this paper attempts to use the idea of robust optimization as well as AHP in an integrated framework to measure the relative efficiency of different units of airlines in Iran. This paper is organized as follows. We first present the problem statement of DEA method in section 2. Section 3 presents an in-depth discussion of the implementation of the proposed DEA-AHP models. Finally, concluding remarks are given in the last section to summarize the contribution of the paper.

\section{Problem statement}

Let $x_{i j}$ be the inputs for a decision unit with $i=1, \ldots, m$ and $y_{r j}$ be the outputs with $r=1, \ldots, s$ and $j=1, \ldots, n$. Let $u_{i}$ and $v_{j}$ be the dual variables associated with $x_{i}$ and $y_{j}$, respectively. The constant to scale DEA model is formulated as follows,

$\max \quad z=\frac{\sum_{r=1}^{s} u_{r} y_{r}}{\sum_{i=1}^{m} v_{i} x_{i}}$ 


$$
\begin{array}{ll}
\text { subject to } \quad & \frac{\sum_{r=1}^{s} u_{r} y_{r j}}{\sum_{i=1}^{m} v_{i} x_{i j}} \leq 1 . \\
& u_{r}, v_{i} \geq 0, \quad j=1, \ldots, n
\end{array}
$$

Model (1) is the basis of DEA and it is solved $j$ times to determine the relative efficiencies of different units. However, since (1) is nonlinear in structure, Charles et al. (1983) recommend a simple modification of the objective function to simplify the structure of the resulted problem as follows,

$$
\begin{array}{ll}
\max & z=\sum_{r=1}^{s} u_{r} y_{r .} . \\
\text { subject to } & \sum_{r=1}^{s} u_{r} y_{r j} \\
& \sum_{i=1}^{m} v_{i} x_{i j} \\
& \sum_{i=1}^{m} v_{i} x_{i .}=1 . \\
& u_{r}, v_{i} \geq 0, \quad j=1, \ldots, n
\end{array}
$$

Note that the first constraint also becomes linear using a simple manipulation. Problem (2) has been widely used for the past three decades and the results are commonly accepted as a tool to measure the relative efficiency of different units. However, when there is uncertainty with the inputs and the outputs, one may use different techniques to make sure that a small change on input/output data does not change the output rankings.

\subsection{Robust optimization}

Consider a linear programming problem of the following form,

$\min c^{\prime} w$

subject to $A w=b$,

$w \geq 0$,

where $w \in R^{n \times 1}$ is the vector of unknown variables, $A \in R^{m \times n}$ and $b \in R^{m \times 1}$ and $c \in R^{n \times 1}$. Let $A$ and $c$ are subject to uncertainty. Therefore, Eq. (3) can be reformulated as follows,

$\min \widetilde{c}^{\prime} w$

subject to $\widetilde{A} w=b$,

$w \geq 0$,

where $\sim$ denotes the uncertainty with $\widetilde{A}=\left[\widetilde{a}_{i j}\right]$. The robust optimization approach presented by Bertsimas and Sim (2004) converts Eq. (4) into the following problem, 
$\min c^{\prime} w$

subject to

$$
\begin{aligned}
& a_{i}^{\prime} w-\Gamma_{i} p_{i}-\sum_{j \in J_{i}} q_{i j} \geq 0 \quad \forall i, \\
& p_{i}+q_{i j} \geq e a_{i j} y_{j} \quad \forall i, j, \\
& -y_{j} \leq w_{j} \leq y_{j} \quad \forall j, \\
& p_{i}, q_{i j} \geq 0, \\
& w \in R^{n \times 1},
\end{aligned}
$$

where $\Gamma_{i}$ determines the uncertainty associated with each input parameter. When $\Gamma_{i}=0$ there is no uncertainty. As $\Gamma_{i}$ increases, the uncertainty also increases. The $e$ is also the vector of uncertain values. The DEA model originally developed by Charnes et al. (1983) is as follows,

(CCR)

$\max$

$$
z=\sum_{r=1}^{s} u_{r} \tilde{y}_{r .}
$$

subject to $\frac{\sum_{r=1}^{s} u_{r} \tilde{y}_{r j}}{\sum_{i=1}^{m} v_{i} \widetilde{x}_{i j}} \leq 1$.

$$
\begin{aligned}
& \sum_{i=1}^{m} v_{i} \tilde{x}_{i .}=1 \\
& u_{r}, v_{i} \geq 0, \quad j=1, \ldots, n
\end{aligned}
$$

where $\tilde{x}$ and $\tilde{y}$ are the uncertain inputs and outputs which are associated with $x$ and $y$, respectively. In Eq. (6) each uncertain parameter lies in an interval of uncertainty. Applying Eq. (5) to Eq. (6) yields,

$$
\begin{array}{ll}
\text { (RCCR)max } & Z \\
\text { subject to } & \sum_{i=1}^{m} v_{i} x_{i .}=1, \\
& \sum_{r=1}^{s} \mathrm{u}_{\mathrm{r}} y_{r .}-z-\Gamma p .-\sum_{j \in J_{i}} q_{r .} \geq 0 \\
& \sum_{i=1}^{m} \mathrm{u}_{\mathrm{i}} y_{i j .}-\sum_{r=1}^{s} u_{r} y_{r j}-\Gamma_{i} p_{j}-\sum_{j \in J_{i}} q_{r j} \geq 0, j=1, \ldots, n \\
& p_{j} q_{r j} \geq e y_{r j} z_{r} \quad \forall r, j \\
& -z_{r} \leq u_{r} \leq z_{r} \quad \forall r \\
& p_{j}, q_{r j} \geq 0, u_{r}, v_{i} \geq 0 .
\end{array}
$$

Problem (7) is linear programming problem where $e$ is a vector of uncertain values, $\Gamma$ is the budget of uncertainty, $p$ and $q$ are new dummy non-negative variables associated with uncertain parameters in (6). As we explained earlier, there are two advantages associated with Bertsimas and Sim's robust model. First, the robust DEA is still linear in the structure although we need to add some additional auxiliary variables. Second, $\Gamma$ adjusts the uncertainty associated with all parameters. Next section, we examine two models (2) and (7) and compare their results using some statistical technique. 


\subsection{DEA-AHP}

In analytical hierachy process (AHP), one may solve a DEA problem only by considering pairwise comparison of different units. Sinuany-Stern et al. (2000) are believed to be the first who introduced the idea of DEA-AHP in a comprehensive form. The proposed model of this paper presents a robust DEA-AHP mehod to handle the uncertainty associated with the input/output data. Consider, for instance, two units of $A$ and $B$, where the robust DEA-AHP is modeled as follows,

$$
\begin{aligned}
& \mathrm{RE}_{\mathrm{AA}} \\
& \mathrm{Max}_{\mathrm{s}}=\mathrm{Z} \\
& \sum_{\mathrm{r}=1}^{\mathrm{u}} \mathrm{u}_{\mathrm{r}} y_{\mathrm{rA}}-\mathrm{Z}-\Gamma_{\mathrm{A}} P_{\mathrm{A}}-\sum_{\mathrm{r}=1}^{\mathrm{s}} \mathrm{q}_{\mathrm{rA}} \geq 0, \\
& \sum_{i=1}^{m} v_{i} \mathrm{x}_{\mathrm{iA}}=1, \\
& \sum_{i=1}^{\mathrm{m}} \mathrm{v}_{\mathrm{i}} \mathrm{x}_{\mathrm{iB}}-\sum_{\mathrm{r}=1}^{\mathrm{s}} \mathrm{u}_{\mathrm{r}} \mathrm{y}_{\mathrm{rB}}-\Gamma_{\mathrm{B}} \mathrm{P}_{\mathrm{B}}-\sum_{\mathrm{r}=1}^{\mathrm{s}} \mathrm{q}_{\mathrm{rB}} \geq 0, \\
& P_{j} q_{r j} \geq e y_{r j} z_{r}, \\
& -z_{r} \leq u_{r} \leq z_{r}, p_{j}, q_{r j} \geq 0 \\
& u_{r}, v_{i} \geq 0 .
\end{aligned}
$$

where $\Gamma$ is defined as $\Gamma=1+\emptyset^{-1} \sqrt{n}$. The model is used for measuring the relative efficiency of unit $A$ compared with unit $B$. Similar model can be used for measuring the relative efficiency of unit $B$ as follows,

$$
\begin{aligned}
& \mathrm{RE}_{B A} \\
& \operatorname{Max}=\mathrm{Z}, \\
& \sum_{\mathrm{r}=1}^{\mathrm{s}} \mathrm{u}_{\mathrm{r}} y_{\mathrm{rB}}-\mathrm{Z}-\Gamma_{\mathrm{B}} P_{\mathrm{B}}-\sum_{\mathrm{r}=1}^{\mathrm{s}} \mathrm{q}_{\mathrm{rB}} \geq 0, \\
& \sum_{i=1}^{m} v_{i} \mathrm{x}_{\mathrm{iB}}=1, \\
& \mathrm{E}_{\mathrm{AA}} *\left(\sum_{i=1}^{\mathrm{m}} \mathrm{v}_{\mathrm{i}} \mathrm{x}_{\mathrm{iA}}\right)-\sum_{\mathrm{r}=1}^{\mathrm{s}} \mathrm{u}_{\mathrm{r}} \mathrm{y}_{\mathrm{rA}}-\Gamma_{\mathrm{A}} \mathrm{P}_{\mathrm{A}}-\sum_{\mathrm{r}=1}^{\mathrm{s}} \mathrm{q}_{\mathrm{rA}} \geq 0, \\
& P_{j} q_{r j} \geq e y_{r j} z_{r}, \\
& -z_{r} \leq u_{r} \leq z_{r}, \\
& p_{j}, q_{r j} \geq 0 \\
& u_{r}, v_{i} \geq 0 .
\end{aligned}
$$

Note that we must solve $\mathrm{RE}_{\mathrm{BB}}$ and $\mathrm{RE}_{\mathrm{AB}}$ models and then we can arrange the pairwise matrix of $\mathrm{AHP}$ as follows,

$r \mathrm{a}_{\mathrm{jk}}=\frac{\mathrm{RE}_{\mathrm{jj}}+R E_{j k}}{\mathrm{RE}_{\mathrm{kk}}+\mathrm{RE}_{\mathrm{kj}}}, \quad r a_{k j}=\frac{1}{r a_{j k}}$.

Now, we can perform ranking policy using AHP technique (Saaty, 1980). 


\section{The results}

In this section, we present the implementation of our proposed model for a real-world case study from Airport industry. Table 1 shows the inputs and the outputs used for our DEA implementation.

Table 1

The inputs and the outputs of RDEA-AHP model

\begin{tabular}{lllll}
\hline \multirow{5}{*}{ Inputs } & \multicolumn{1}{c}{ Title } & Description & Mean & Std \\
\cline { 2 - 6 } & Number of Employees & Sum of the people who work in the airport & 151.43 & 148.08 \\
& Terminal area & Area of terminal & 16885.24 & 21736.94 \\
& Length of runway & Surface of the asphalt road & 5175.29 & 2023.61 \\
\hline \multirow{2}{*}{ Outputs } & $\begin{array}{l}\text { Number of } \\
\text { movements }\end{array}$ & Flights of domestic \& international & 11332.71 & 19813.35 \\
& Number of Passengers & passengers & 1389699.8 & 2453794.8 \\
& Amount of Cargo & Cargo & 14104.29 & 25241.36 \\
\hline
\end{tabular}

Table 2 demonstrates details of our input/output parameters. Based on the information provided in Table 2 and

Table 2

The inputs and the outputs of 21 airports

\begin{tabular}{|c|c|c|c|c|c|c|c|}
\hline & Airport & $\begin{array}{l}\text { Amount } \\
\text { of Cargo }\end{array}$ & $\begin{array}{l}\text { Number of } \\
\text { Passengers }\end{array}$ & $\begin{array}{l}\text { Number of } \\
\text { movements }\end{array}$ & $\begin{array}{l}\text { Length of } \\
\text { runway }\end{array}$ & $\begin{array}{c}\text { Terminal } \\
\text { area }\end{array}$ & $\begin{array}{l}\text { Number of } \\
\text { Employees }\end{array}$ \\
\hline 1 & Imam Khomeini & 92426 & 3939532 & 27392 & 4198 & 78000 & 560 \\
\hline 2 & Mehrabad & 81649 & 10846868 & 89514 & 8150 & 76370 & 573 \\
\hline 3 & Mashad & 23839 & 4109982 & 29585 & 7736 & 38778 & 218 \\
\hline 4 & Tabriz & 7232 & 853580 & 6747 & 7171 & 11800 & 166 \\
\hline 5 & Esfahan & 15988 & 1525183 & 13262 & 8794 & 21050 & 215 \\
\hline 6 & Ardebil & 872 & 213765 & 2064 & 5800 & 2900 & 56 \\
\hline 7 & Bandarabas & 5664 & 826158 & 7088 & 7133 & 9300 & 146 \\
\hline 8 & Shiraz & 22177 & 1902506 & 19438 & 8601 & 23000 & 197 \\
\hline 9 & Zahedan & 4886 & 348196 & 2722 & 4250 & 6800 & 109 \\
\hline 10 & Kerman & 4839 & 552553 & 3459 & 5873 & 6550 & 115 \\
\hline 11 & Abadan & 1603 & 255835 & 2030 & 5370 & 14754 & 73 \\
\hline 12 & Ahvaz & 14486 & 1522122 & 13050 & 3400 & 7920 & 34 \\
\hline 13 & Rasht & 2483 & 307646 & 3236 & 3050 & 3500 & 86 \\
\hline 14 & Yazd & 2781 & 330040 & 3033 & 4100 & 11100 & 93 \\
\hline 15 & Sari & 2540 & 155775 & 1260 & 2650 & 7296 & 89 \\
\hline 16 & Boshehr & 3371 & 273681 & 2042 & 4469 & 7072 & 114 \\
\hline 17 & Oroumieh & 2174 & 296890 & 2377 & 3250 & 7800 & 91 \\
\hline 18 & Kermanshah & 2036 & 489730 & 4766 & 3400 & 7700 & 94 \\
\hline 19 & Gorgan & 1873 & 215387 & 2280 & 2993 & 3200 & 65 \\
\hline 20 & Larestan & 2317 & 106869 & 1470 & 3229 & 8400 & 47 \\
\hline 21 & Birjand & 954 & 111398 & 1172 & 5064 & 1300 & 39 \\
\hline
\end{tabular}

Table 3 we ran the proposed the DEA-AHP and the results of our ranking are summarized in Table 4.

Table 4

The results of ranking of DEA-AHP

\begin{tabular}{lccccccccccccccccccccc}
\hline Airport & 12 & 2 & 8 & 1 & 3 & 5 & 7 & 13 & 4 & 21 & 10 & 9 & 6 & 18 & 19 & 16 & 20 & 17 & 15 & 14 & 11 \\
\hline Efficiency (\%) & 12 & 8 & 6 & 5 & 5 & 5 & 4 & 4 & 4 & 4 & 4 & 4 & 4 & 4 & 4 & 4 & 4 & 3 & 3 & 3 & 3 \\
Ranking & 1 & 2 & 3 & 4 & 5 & 6 & 7 & 8 & 9 & 10 & 11 & 12 & 13 & 14 & 15 & 16 & 17 & 18 & 19 & 20 & 21 \\
\hline
\end{tabular}


We have also implemented the proposed robust DEA-AHP method to measure the relative efficiency of airports and the results are summarized in Table 5.

\section{Table 5}

The results of ranking of robust DEA-AHP

\begin{tabular}{lccccccccccccccccccccc}
\hline Airport & 12 & 2 & 3 & 8 & 1 & 5 & 7 & 13 & 4 & 10 & 21 & 9 & 19 & 6 & 18 & 17 & 20 & 16 & 15 & 11 & 14 \\
\hline Efficiency (\%) & 11 & 9 & 6 & 6 & 5 & 5 & 4 & 4 & 4 & 4 & 4 & 4 & 4 & 4 & 4 & 3 & 3 & 3 & 3 & 3 & 3 \\
Ranking & 1 & 2 & 3 & 4 & 5 & 6 & 7 & 8 & 9 & 10 & 11 & 12 & 13 & 14 & 15 & 16 & 17 & 18 & 19 & 20 & 21 \\
\hline
\end{tabular}

As we can observe from the results of Table 5, there are not much difference between the ranking of these two methods. In order to confirm this observation, we have implemented Spearman correlation between the results of regular and robust DEA-AHP and the result is $r_{\text {spearman }}=0.999999758$, which confirms our claim.

\section{Conclusion}

In this paper, we have presented an improved DEA-AHP method where the input/output parameters are subject to uncertainty. The proposed model of this paper not only enjoys the advantages of regular DEA-AHP but also it can incorporate the uncertainty associated with all the data. Therefore, the final ranking of the results will not be changed as the input data are changed. The proposed model of this paper has been implemented for a real-world case study of airport industry and the results are compared with traditional DEA-AHP.

\section{Acknowledgment}

This paper was financially supported by Islamic Azad university of Naragh and the authors would like to sincerely thank them for their financial support. The authors are grateful on constructive comments of the reviewers on earlier version of this work.

\section{References}

Ben-Tal, A., Nemirovski, A. (1999). Robust solutions of uncertain linear programs, Operations Research Letters, 25 (1), 1-13.

Bertsimas, D., \& Sim, M. (2003). Robust discrete optimization and network flows. Mathematical Programming Series B, 98, 49-71.

Charnes A, Cooper, W. W., \& Rhodes, E. (1978). Measuring the efficiency of decision making units. European Journal of the Operational Research, 2, 429-44.

Charnes A, Cooper W. W., Lewin, A., \& Seiford, L. M. (1994). Data envelopment analysis: theory, methodology and applications. Massachusetts: Kluwer Academic Publishers.

Che, Z. H., Wang, H. S., \& Chuang, Ch-L. (2010). A fuzzy AHP and DEA approach for making bank loan decisions for small and medium enterprises in Taiwan. Expert Systems with Applications, 37(10), 7189-7199.

Roghanian, E., \& Foroughi, A. (2010). An empirical study of Iranian regional airports using robust data envelopment analysis. International Journal of Industrial Engineering Computations, 1(1), $65-72$.

Saaty, T. L. (1980). The Analytic Hierarchy Process: Planning, Priority Setting, Resource Allocation, ISBN 0-07-054371-2, McGraw-Hill.

Sadjadi, S.J., \& Omrani, H. (2008). Data envelopment analysis with uncertain data: An application for Iranian electricity distribution companies, Energy Policy 36, 4247-4254.

Sadjadi, S.J., \& Omrani, H. (2009). A bootstrapped robust data envelopment analysis model for efficiency estimating of telecommunication companies in Iran, Telecommunications Policy, 34(4), 221-232. 
Soyster, A.L. (1973). Convex programming with set-inclusive constraints and applications to inexact linear programming, Operations Research, 21, 1154-1157.

Sinuany-Stern, Z., Mehrez, A., \& Hadad, Y. (2000). An AHP/DEA methodology for ranking decision making units. International Transactions in Operational Research, 7(2), 109-124. 